BLS 33, No 1 2007. DOI: http://dx.doi.org/10.3765/bls.v33i1.3544

(published by the Berkeley Linguistics Society and the Linguistic Society of America)

\title{
Language and Gesture on Ishigaki Island ${ }^{1}$
}

\author{
MAKIKO TAKEKURO \\ Waseda University
}

\section{Introduction}

Based on the results of many years of cross-linguistic research in a number of field sites where non-Indo-European languages are spoken, a functional typology of linguistic encoding of space was presented and three spatial frames of reference were identified: Relative (ego-centric), Absolute (environmental), and Intrinsic (Pederson et al. 1998; Levinson 2003). In the relative system, referents are referred to by the spatial configurations vis-a-vis the speaker (e.g. 'right' and 'left'), as in "The man stands on my right." The spatial relation changes as the speaker's location changes. In the absolute system, the frame of reference requires fixed bearings such as 'north', 'south', 'east', and 'west,' as in 'Okinawa is on the south of Tokyo." The spatial relation is stable as the orientations are based on fixed environmental features. In the intrinsic system, the frame of reference is identified in terms of the referent's own characteristics -i.e., 'front,' 'back,' 'mouth,' and 'foot,' as in "Flowers touch the mouth of the vase.",

While contemporary Japanese possesses the three types of frame of reference (hereafter, FoR), it is believed to rely overwhelmingly on the relative system, at least in the Metropolitan Tokyo area (Pederson et al. 1998). The terms migi ('right') and hidari ('left') are considered the dominant linguistic encodings of space in Japanese. However, the literature on language and space in Japan is so scarce that we can hardly validate the claim of the dominance of the relative FoR in Japanese spatial cognition. The aim of this paper is to exhibit a communicative practice based on the absolute FoR in a rural community outside the Japanese mainland. By presenting linguistic and gesture data collected on Ishigaki Island in Okinawa, this paper also argues that the choice of the FoR is not predetermined but changes according to interactional contexts.

\footnotetext{
${ }^{1}$ This research was supported through Hakuho Foundation's Language, Culture and Education Fellowship for 2006-2007 and the Japan Society for the Promotion of Science (Grant-in-Aid for Scientific Research for Young Scholars (Startup) \#18820033), to which I am grateful. I also wish to thank those who participated in this study.

${ }^{2}$ Other researchers have defined these notions using different terms (See Kataoka 2002). In this paper, I will use Levinson's notions and terminology as a point of departure.
} 
Makiko Takekuro

\section{Space and communicative practice in communities outside Tokyo}

Recently, studies investigating the use of the spatial frame of reference in communities outside the Metropolitan Tokyo show that the absolute FoR is more frequently used in Japanese than has been considered.

Inoue (2002) reveals that the city of Kouchi in the Shikoku region of Japan is a community where the absolute FoR is ordinarily used. Based on interviews and questionnaires among 43 elementary school students, Inoue (2005) found several aspects of spatial cognition and language use in Kouchi. First, 8.5\% of her subjects claim that they apply cardinal direction terms to body parts, as in "My north-east cavity aches." Second, the frequency of using cardinal direction terms increases as the size of space referred to becomes larger. For example, in describing "indoor space" and "outdoor with boundaries" (e.g. gates, school buildings, and outdoor stairs), $35 \%$ and $60 \%$ of her subjects claim to use cardinal direction terms, respectively. On the contrary, in describing "big outdoors," $70 \%$ of her subjects claim that they would use cardinal direction terms. Thus, subjects switch the FoR from relative to absolute, as the referred space becomes larger. Third, in the downtown, the common FoR has shifted from absolute to relative over time. In mountainous areas, there is an ongoing shift in the use of FoR from absolute to relative. Inoue's studies report the changes in the use of the FoR, however, they demonstrate that the absolute FoR is still used in the community.

Hosoma (2003) examines interactions with a master of the local traditional festival, Nishiure Dengaku, in Shizuoka, Japan. As the master's gestural description of the arrangement of items that are indispensable to the festival is always accurate to the compass, Hosoma claims that the master's gestures are based on the absolute FoR.

Kataoka (2005) investigates the use of FoR in street signboards in outskirts of the city of Nagoya. Contrary to the claim that the relative FoR is common in Japanese spatial cognition, the absolute FoR is most frequently used in street signboards. For example, while the relative FoR is used to describe location in proximity, the absolute FoR is used to describe destination in distance. He concludes that the absolute FoR plays an equally important role as the relative FoR in Japanese wayfinding.

These studies altogether suggest that the absolute FoR is indeed observable in some geographical and interactional contexts. A careful examination of spatial cognition in various Japanese communities is necessary before we can conclude that the relative FoR is dominant in Japan. This paper thus investigates the spatial FoR in a rural community outside the Japanese mainland, Ishigaki Island.

\section{Ishigaki Island}

Ishigaki Island is one of the Yaeyama Islands, the southernmost island group in Japan, lying 420 kilometers southwest of Naha on the Main Okinawa Island. ${ }^{3}$ It

3 Ishigaki Island is located 2,200 kilometers south of Tokyo and 250 kilometers west of Taiwan. 
belongs to the subtropical climate zone. The island is about $120 \mathrm{~km}$ in circumference and surrounded by coral reeves and beaches. Every year more than seventy thousand tourists visit the island, which has a significant impact on the island's economy. Among the island's estimated population of 47,000, ninety percent lives in Ishigaki shigaichi (downtown), which is marked by parallel roads leading a few blocks north from the port and by crossroads running west-east along the coast (See Maps $2 \& 3$ ).

On Ishigaki Island, speakers, especially of the older generation, speak the Yaeyama dialect or varieties of the Ryuukyuu Dialect in addition to Standard Japanese. ${ }^{4}$ Today, many young speakers claim that they cannot speak or understand the Yaeyama dialect. But their speech contains accentual patterns and lexicons that are characteristics of the Yaeyama or the Ryuukyuu dialect.

\section{Data analysis}

This section presents data collected in several field trips to Ishigaki Island since September 2006. The analysis reveals that (1) the absolute FoR is ordinarily observed in Ishigaki speakers' speech and gesture; and (2) speakers choose the FoR according to the interlocutors' background. ${ }^{5}$

\subsection{Cardinal direction terms in the Yaeyama (Ishigaki) dialect}

Cardinal direction terms used on Ishigaki Island are different from those in Standard Japanese. Table 1 shows a list of cardinal direction terms relevant to this study in the Naha and the Yaeyama dialects, Standard Japanese, and English. ${ }^{6}$

Table 1: Cardinal direction terms in the Yaeyama and Naha dialects

\begin{tabular}{|c|c|c|c|}
\hline English & $\begin{array}{c}\text { Standard } \\
\text { Japanese }\end{array}$ & Naha Dialect & $\begin{array}{c}\text { Yaeyama } \\
\text { Dialect }\end{array}$ \\
\hline 'east' & higashi & Agari & aaru \\
\hline 'west' & nishi & Iri & iiru \\
\hline 'south' & minami & hai/pai & hai/pai \\
\hline 'north' & kita & nishi/nisu & nishi/nisu \\
\hline
\end{tabular}

The Yaeyama dialect has its own cardinal direction terms that are slightly different from those in the Naha dialect, but no instance of the terms spoken in the Yaeyama dialect was found during my data collection. Ishigaki speakers that I

\footnotetext{
${ }^{4}$ Varieties spoken on the Yaeyama, Miyako, Okinawa, and Amami Islands are known as Ryuukyuu Dialect as a whole. Since Ishigaki Island's population includes groups of settlers whose ancestors came from these and other islands, speakers of the older generation speak dialect varieties that their ancestors spoke on their home islands. However, those islands are so far apart in the Pacific Ocean that dialect varieties are often mutually unintelligible.

${ }^{5}$ Here, Ishigaki speakers refer to natives of Ishigaki Island.

${ }^{6}$ Here, the Naha dialect refers to a variety of the Ryuukyuu Dialect.
} 
encountered used cardinal direction terms not in the Yaeyama dialect but either in the Naha dialect or in Standard Japanese, as shown in the following analysis.

\subsection{The absolute frame of reference in speech}

This section examines how Ishigaki speakers describe space in their everyday speech. In naturally-occurring interaction I recorded, no speaker used cardinal direction terms in reference to body parts, unlike speakers in Kouchi in Inoue's studies. However, in reference to objects inside or near the house, Ishigaki speakers sometimes use cardinal direction terms, as in (1) and (2).

(1) The speaker (age 80) talks to his grandson who is looking for scissors:

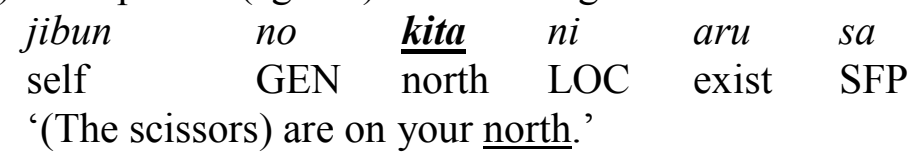

(2) Standing at the entrance space, the speaker talks to her neighbor and the cat:

\begin{tabular}{|c|c|c|}
\hline & $\begin{array}{l}n i \\
\mathrm{LOC}\end{array}$ & $\begin{array}{l}\text { mawatte } \\
\text { go around }\end{array}$ \\
\hline
\end{tabular}

'Go around (the house) to the west and come in.'

When speakers talk about local geography, they often use cardinal direction terms, as in (3) and (4). Example 3 shows a common way of conveying the locative information in downtown Ishigaki.

(3) The speaker informs her friend about the place to meet:

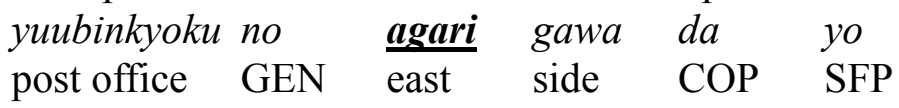

'(We'll) meet on the east side of the post office.'

(4) The speaker describes a route to a stranger:

$\begin{array}{llllll}\text { soko } & \text { itte niken } & \text { sanken } & \text { yonkenme } & \text { desu } & \text { yo } \\ \text { there } & \text { go second third fourth house } & \text { COP } & \text { SFP } \\ \text { konkuri } & \text { arimasuyo } & \text { sono } & \underline{\text { nishi desu }} & \text { yo } & \\ \text { concrete } & \text { exist.COP.SFP } & \text { the } & \text { west } \text { COP } & \text { SFP } & \end{array}$

'(When you) go there and on the second, third, and fourth house, there is a concrete building. (It's) on the west side of the building.'

Just like Inoue (2005) finds in the city of Kouchi, on Ishigaki Island, too, the larger the size of the referred space becomes, the more likely Ishigaki speakers would use cardinal direction terms. In such situations, the use of cardinal direction terms often occurs with gesture which accurately points the actual direction of the space mentioned. This point will be analyzed in 4.4. Overall, the use of cardinal direction terms is common in everyday speech among Ishigaki speakers. This, 
however, does not automatically mean the dominance of the absolute FoR in Ishigaki speakers' speech. In fact, speakers on Ishigaki Island choose other spatial frames of reference depending on context, as illustrated in the next section.

\subsection{The different frames of reference for different interlocutors}

As a popular holiday resort and place for retired life, many people visit or move to the island throughout the year. To most islanders living and working in downtown Ishigaki, interaction with tourists or new settlers from other prefectures is an everyday matter. Then, what happens when local islanders and tourists from other prefectures meet and talk about space? Which FoR is chosen? This section analyzes how Ishigaki speakers in downtown Ishigaki describe a direction to non-Ishigaki speakers and examines whether or not the FoR used in Ishigaki speakers' directional descriptions remains constant across different interlocutors.

Before analyzing the data, I should introduce the local practice of describing a direction. In downtown Ishigaki, people use agaru ('to go up/climb') to go towards the direction of Mt. Omoto from the ocean and sagaru/oriru ('to go down/descend') to go towards the ocean from the direction of Mt. Omoto (Map 2). The terms are said to reflect the gentle slope leading to Mt. Omoto from the ocean. The same expressions are used in the town of Shiraho to the northwest of downtown Ishigaki, though compass directions of what agaru and sagaru/oriru point to in Shiraho and downtown Ishigaki are different (Map 1).

Map 1: Ishigaki Island ${ }^{7}$

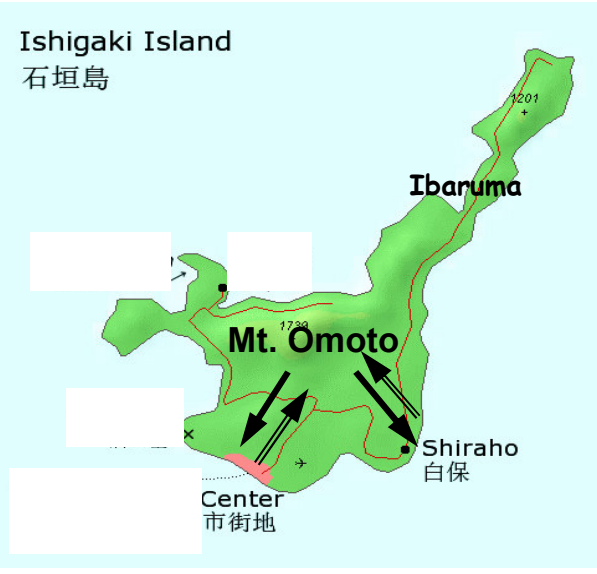

Map 2: Downtown Ishigaki ${ }^{8}$

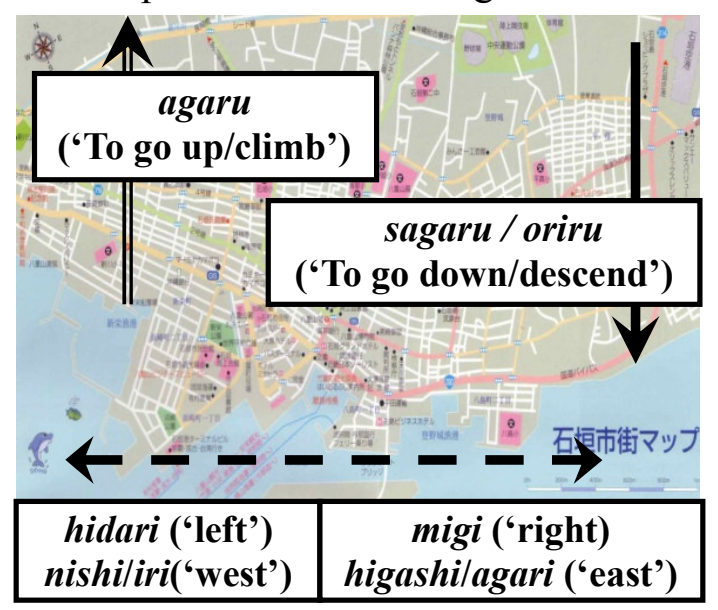

In downtown Ishigaki, spatial description is based on two coordinates: the south-north and east-west. To describe the south-north coordinate, as mentioned earlier, the terms agaru and sagaru/oriru are used. I heuristically consider that

\footnotetext{
${ }^{7}$ I used the map taken from http://wikitravel.org/en/Image:Map-ishigaki.png and modified.

8 This map is taken from http://www.yaeyama.or.jp. The arrows and the explanations in the boxes were added by the researcher.
} 
these terms are based on the intrinsic FoR. ${ }^{9}$ To describe the west-east coordinate along which several long roads run parallel, the terms hidari/migi ('left/right'), nishi/higashi ('west/east') of Standard Japanese, or iri/agari ('east/west') of the Naha dialect are used. ${ }^{10}$ In downtown Ishigaki, I consider the terms left/right as using the relative FoR and the terms west/east as using the absolute FoR.

Using these frames of reference as a point of departure, I investigated which spatial FoR would be used to a pair of non-Ishigaki speakers and to a pair of native Ishigaki speakers when the two pairs separately asked for directions (to locations A and B on Map 3) from randomly-chosen subjects who are natives of Ishigaki. ${ }^{11}$ Data-collecting interviews were conducted on the flat part of downtown Ishigaki, in order to avoid the geographic bias and not to influence speakers to use the terms agaru, oriru, and sagaru that inherently include upward and downward movements.

\section{Map 3: Two directions interviewed in downtown Ishigaki ${ }^{12}$}

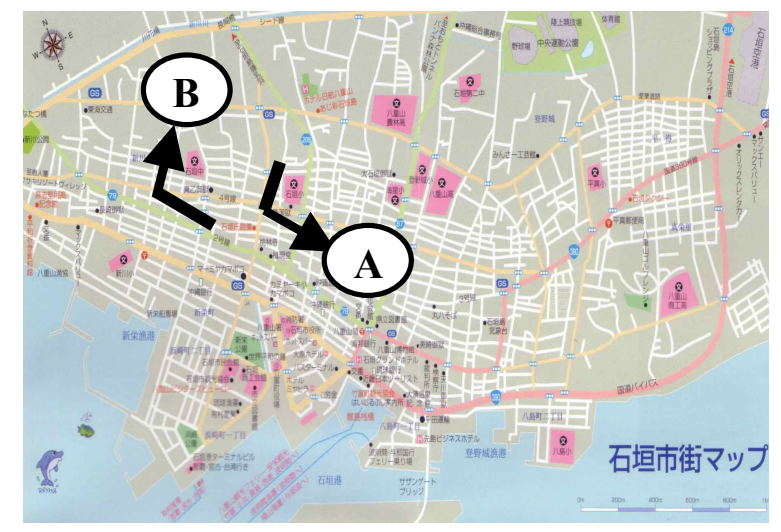

Tables 2 and 3 below show the results of the interviews and suggest that Ishigaki speakers tend to discern the use of FoR according to interlocutors.

\footnotetext{
${ }^{9}$ This categorization is different from Levinson's (2003). Levinson would consider that these expressions show the absolute FoR that is based on the fixed geographic features such as mountains and the sea. In the case of Ishigaki Island, the same expressions agaru, oriru/sagaru are used in Shiraho to describe not the south-north but west-east coordinate, as indicated on Map 1. So the use of the terms is based on the local intrinsic characteristics rather than the absolute compass . ${ }^{10}$ Precisely speaking, the west/east distinction is not accurate to compass. It has to be north-west/south-east, but people conventionally use the terms 'west' and 'east' to describe the direction indicated in the dotted line on Map 2.

${ }^{11}$ Here, locations A and B are heuristic. The directions and routes that people described were not limited to the ones that appear on the map.

${ }^{12}$ This map again taken from http://www.yaeyama.or.jp includes additional information.
} 
Table 2: The FoR to describe location $\mathrm{A}^{13}$

Table 3: The FoR to describe location B

\begin{tabular}{|c|c|c|}
\hline FoR & $\begin{array}{c}\text { To non-Ishigaki } \\
\text { Speakers }\end{array}$ & $\begin{array}{c}\text { To Ishigaki } \\
\text { Speakers }\end{array}$ \\
\hline Relative & $\begin{array}{c}72 \% \\
(13 / 18)\end{array}$ & $\begin{array}{c}13 \% \\
(2 / 15)\end{array}$ \\
\hline \multirow{2}{*}{ Absolute } & $\begin{array}{c}17 \% \\
(3 / 18)\end{array}$ & $\begin{array}{c}47 \% \\
(7 / 15)\end{array}$ \\
\hline \multirow{2}{*}{ Intrinsic } & $33 \%$ & $53 \%$ \\
& $(6 / 18)$ & $(8 / 15)$ \\
\hline
\end{tabular}

\begin{tabular}{|c|c|}
\hline $\begin{array}{c}\text { To non-Ishigaki } \\
\text { Speakers }\end{array}$ & $\begin{array}{c}\text { To Ishigaki } \\
\text { Speakers }\end{array}$ \\
\hline $85 \%$ & $20 \%$ \\
$(11 / 13)$ & $(2 / 10)$ \\
\hline $15 \%$ & $20 \%$ \\
$(2 / 13)$ & $(2 / 10)$ \\
\hline $46 \%$ & $90 \%$ \\
$(6 / 13)$ & $(9 / 10)$ \\
\hline
\end{tabular}

First, let me explain the results in Table 2. The two pairs of non-Ishigaki and native-Ishigaki speakers collected descriptions of the route to location A. As shown in the left column of Table 2, most subjects used the term hidari ('left') when they explained the route to non-Ishigaki speakers.

(5) kono michi o itte $X$ ni tsuitara shingou o hidari ni magatte... this road $\mathrm{O}$ go $\mathrm{X}$ LOC arrive.then signal O left LOC turn 'Go on this street and (when you) arrive at X, turn left at the signal...'

Some used the intrinsic expression oriru or sagaru combined with hidari as in (6).

(6)

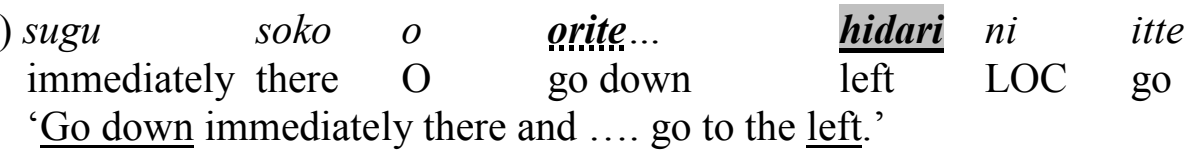

Then, the pair of native Ishigaki speakers asked the same question. As appears in the right column of Table 2, subjects did not use the term hidari ('left') when they talked to natives. Rather, they used cardinal direction terms such as higashi and agari or/and the intrinsic expression oriru, as in (7) and (8).

$\begin{array}{cllllll}\text { (7) Zya } & \text { no } & \text { kado } & o & \text { orite } & \text { agari } & \text { sa } \\ \text { Zstore } & \text { NOM } & \text { corner } & \text { O } & \text { descend } & \text { east } & \text { SFP }\end{array}$

'Go down at the corner of Store Z and it's on the east.'

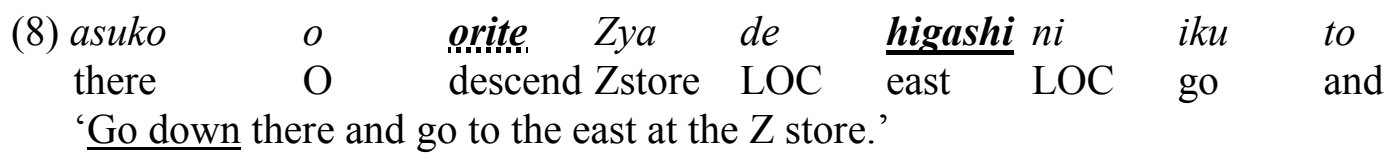

Among native Ishigaki speakers, subjects prefer to use the intrinsic and absolute frames of reference rather than the relative FoR. Thus, whether or not interlocutors are native Ishigaki speakers seems to make a difference in subjects'

${ }^{13}$ The total percentage in the columns is over $100 \%$, because some speakers use more than one FoR in one turn. 
choice of the FoR in spatial descriptions of downtown Ishigaki.

Next, the same pairs of speakers asked a totally different set of subjects to describe the route to location B as appeared on Map 3. The majority of the new subjects used the relative FoR to the pair of non-Ishigaki speakers, as in (9).

$\begin{array}{lllll}\text { (9) gasorinsutando } & o & \underline{\text { migi }} & n i & \text { magatte } \\ \text { gas station } & \text { O } & \text { right } & \text { LOC } & \text { turn } \\ \text { 'Turn right at the gas station.' } & & & \end{array}$

Half of the subjects combined the relative FoR with the intrinsic expression such as agaru, as in (10).

$\begin{array}{lllll}\text { gasorinsutando } & o & \underline{\text { migi }} & n i & \text { agatte. } \\ \text { gas station } & \text { O } & \text { right } & \text { LOC } & \text { go up } \\ \text { 'Go up to the right at the gas station.' } & & \end{array}$

On the other hand, when native Ishigaki speakers talked to each other, the majority of the subjects only used the intrinsic expression, agaru, as in (11).

$\begin{array}{lll}\text { (11) gasorinsutando } & \text { no kado o } & \text { agatte } \\ \text { gas station } & \text { NOM corner O } & \text { go up } \\ \text { 'Go up at the corner of the gas station.' } & \end{array}$

Without using expressions based on the relative FoR, native Ishigaki speakers can understand which way to turn by the expression agaru. Furthermore, only $20 \%$ of the subjects used the term kita ('north') to indicate the direction of the turn, although their descriptions also included the intrinsic expression agaru. Thus, unlike the east-west grid, the north-south grid was not described by cardinal direction terms in downtown Ishigaki. Having the intrinsic expressions such as agaru and sagaru/oriru seems to suffice, which results in no need to use the cardinal direction terms for the north-south grid.

The results show that speakers in downtown Ishigaki commonly use the three types of FoR in their spatial description but discern the use of FoR depending on interlocutors. In talking to non-Ishigaki speakers, they tend to use the relative FoR, while preferring the intrinsic or/and absolute FoR among the locals. I also found that those who used the absolute FoR to non-Ishigaki speakers had limited contact with non-Ishigaki speakers, such as dry cleaning company's workers, fish-market wholesalers, shoppers of the older generations, compared to those in service industries who routinely interact with tourists in their everyday lives. Those with frequent contact with tourists and outsiders tend to switch their FoR depending on interlocutors, whereas those with limited contact with tourists and outsiders tend to maintain their routine practice of using the intrinsic FoR among locals, which was also observed in interaction with non-Ishigaki speakers. This is, however, my 
informal observation and requires more careful examination.

\subsection{The use of gesture}

This section analyzes the use of gesture in Ishigaki speakers' speech. The description of cardinal directions in Ishigaki speakers' speech is often matched by a parallel directional precision in their gesture. ${ }^{14}$

When the names of cities, islands, and countries are mentioned, co-occurring gesture tends to point to the cardinal direction of the locations mentioned. In (12), the speaker (S), who is a taxi driver, was aware of cardinal direction when he mentioned cities and islands outside Ishigaki Island, even in a house that he visited for the first time. The pictures below show that his hands moved to and accurately pointed to the geographic location of Okinawa (Naha) and Yonaguni Island with respect to his location.

(12) The speaker talks about how people on different islands in Okinawa Prefecture refer to the islands differently.

$\begin{array}{clllllll}\text { S: boku nanka } & \text { wa } & \text { ne } & \text { okinawahontou naha } & n i & i k u \\ \text { I } & \text { sort } & \text { SUB } & \text { SFP } & \text { Okinawa Island Naha } & \text { LOC } & \text { go }\end{array}$

$\begin{array}{llllllll}\text { tokini } & w a & n e & \text { Okinawa } & n i & i k u & \text { tte } & i u \\ \text { when } & \text { SUB } & \text { SFP } & \text { Okinawa } & \text { LOC } & \text { go } & \text { Q } & \text { say }\end{array}$

"When I visit Main Okinawa Island or Naha, I'd say “(I) go to Okinawa,",

Pictures 1 \& 2: His right hand points to Okinawa

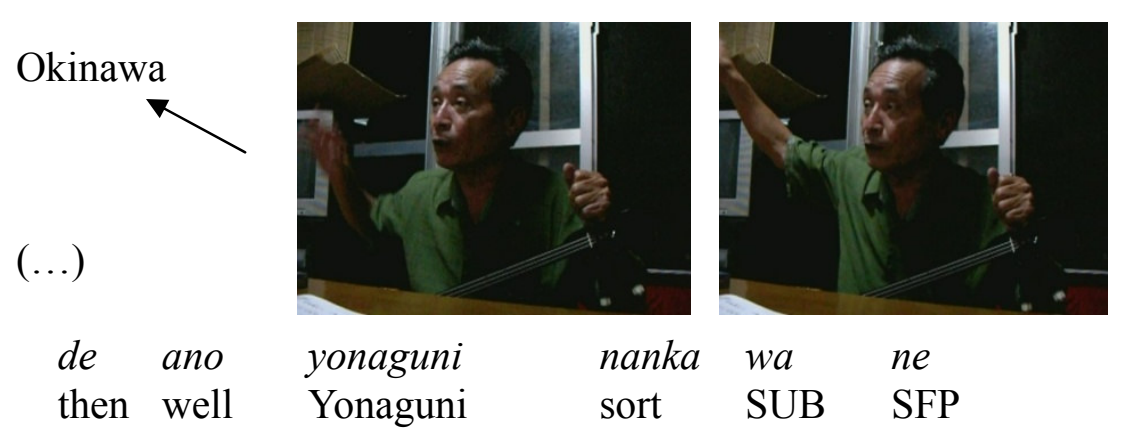

kocchini kuru tte iu no o shika ni iku here LOC come Q say NOM o Shika LOC go 'On Yonaguni Island, when they come to Ishigaki, they'd say "(I) go to Shika."'

\footnotetext{
${ }^{14}$ I must add, though, that compared to Guugu Yimithirr's use of gesture as illustrated in Haviland's studies (1993, 1998, 2000), Ishigaki speakers' gesture is much less salient and accurate to the compass.
} 
Makiko Takekuro

Pictures 3-5: His left hand shows the trip from Yonaguni to Ishigaki
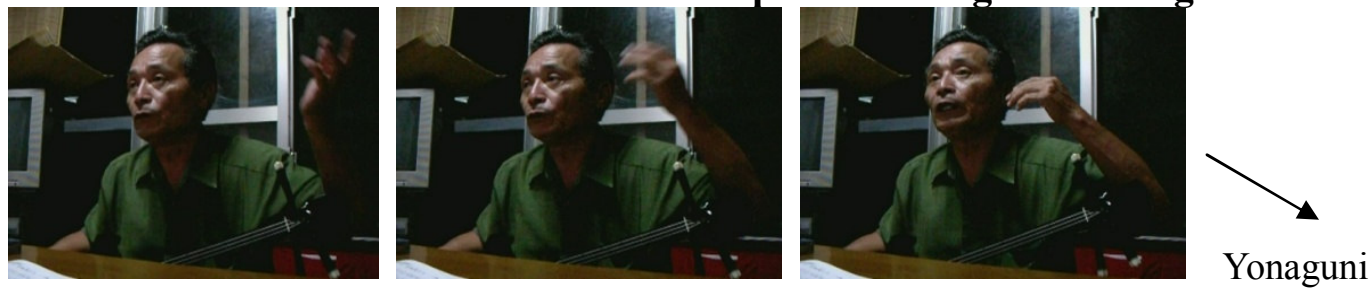

As he mentions locative nouns such as the Main Okinawa Island, the city of Naha, and Yonaguni Island, his co-occurring gestures almost accurately point to the directions of the locations. But when the same speaker drives his taxi and talks to passengers who are both islanders and outsiders, he almost only uses the terms 'right' and 'left' to explain the local geography. In other words, the relative FoR is preferred when things are visible and passing by quickly through car windows, while the absolute FoR is used when things are not visible and unmovable. For example, when he communicates with the taxi company's staff through radio contact so that he could pick up passengers waiting at some specific place, both he and the staff use the cardinal direction terms and describe the meeting place. Visibility seems to be one of the factors that can help speakers to decide which FoR to use.

The next example shows that gesture was accurate to cardinal direction more than speech. In (13), the fisherman (T) talked to his friend (M) about the typhoon that hit Ishigaki in September 2006. T was sitting facing north. When M asked T from which direction the typhoon wind blew in Ibaruma where the fisherman's family lives (see Map 1), T's right hand pointed to the 'east' and made a gesture indicating the wind from the east as in Picture 6, even though he said that the wind blew from the 'south.' Then he corrected his speech immediately and said 'east,' and made a gesture indicating the wind from the east as in Pictures 7 and 8.

(13) $\mathrm{M}:$

$\begin{array}{lllllll}\text { are } & \text { wa } & \text { umi } & \text { kara } & \text { no } & \text { kaze } & k a ? \\ \text { that } & \text { TOP } & \text { ocean } & \text { from } & \text { GEN } & \text { wind } & \text { Q }\end{array}$

'Was the wind coming from the ocean?'

T: sou minami kara no kaze

yes south from GEN wind

'Yes, it was the wind from the south.'

Picture 6: Minami kara no kaze ('Wind from the south')
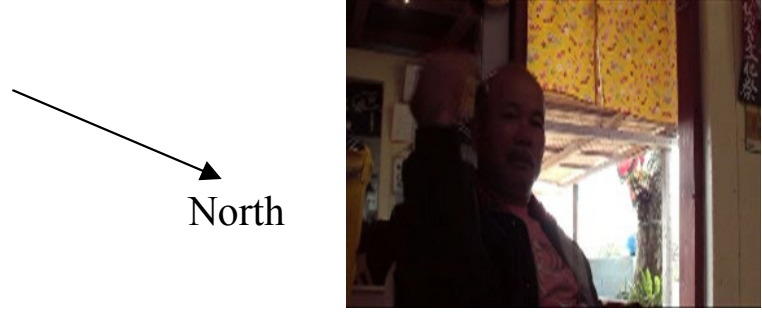
M: minami kara no kaze ka

south from GEN wind SFP

'Oh, it was the wind from the south.'

$\mathrm{T}:$ iya $\underline{\text { minami janai } \underline{\text { higashi }}}$

no south NEG east

'No, not from the south, (it was from) the east.'

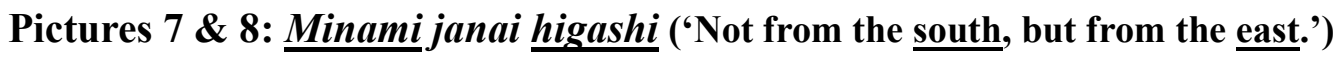
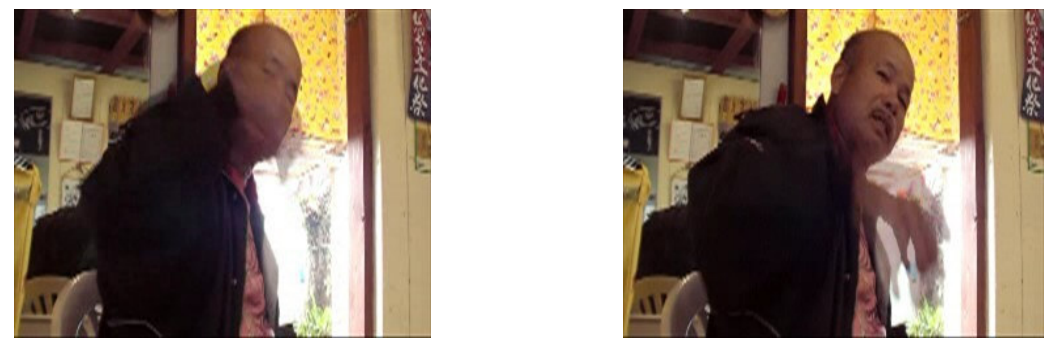

These examples demonstrate a high level of compass-based use of directional expressions in speech and gesture among Ishigaki speakers. The gestural practices of Ishigaki speakers are reinforced by the frequent use of cardinal directional terms in speech. Furthermore, living environments on Ishigaki Island seem to be related to directional accuracy in Ishigaki speakers' speech and gesture. For instance, on this small island surrounded by the sea, the direction of the sea and the south towards which the entrance of residences face serve as crucial reference points for people's lives. Ishigaki speakers' perceiving and expressing direction in terms of the compass will need further investigation.

\section{Conclusions}

This paper has demonstrated that the absolute FoR is commonly used in Ishigaki speakers' interaction together with the relative and intrinsic frames of reference. Unlike some studies that tend to argue for a one-to-one correspondence between a variety of language and the use of a certain FoR, the results obtained in this research thus far suggest that Ishigaki speakers discern the use of the special FoR according to interactional contexts. However, this study is just a beginning. More detailed studies on Ishigaki Island or in other island communities are necessary for an understanding of space in speech and gesture.

\section{References}

Haviland, John. 1993. Anchoring, iconicity, and orientation in Guugu Yimithirr pointing gestures. Journal of Linguistic Anthropology 3(1): 3-45.

Haviland, John. 1998. Guugu Yimithirr cardinal directions. Ethos 26(1): 7-24. 
Haviland, John. 2000. Pointing, gesture spaces, and mental maps. In D. McNeill, ed., Language and gesture, 13-46. Cambridge: Cambridge University Press.

Inoue, Kyoko. 2002. Soutai to fuhen no hazama de: kuukan shijiwaku ni yoru komyunikeeshon [Between relative and universal: communication by spatial reference frame]. In T. Ohori, Ninchi gengogaku II: Kategoriika [Conigitive linguistics 2: Categorization], 11-35. Tokyo: University of Tokyo Press.

Inoue, Kyoko. 2005. Kuukan ninchi to komyunikeeshon [Spatial cognition and communication]. In S. Ide and M. Hiraga, eds., Kouza shakaigengokagaku 1: ibunka to komyunikeeshon [Sociolinguistic sciences 1: Different cultures and communication], 118-128. Tokyo: Hitsuji Publishers.

Kataoka, Kuniyoshi. 2002. Linguistic anthropological research on spatial cognition in European and non-European settings. Language and Culture 6: 121-150. Aichi University's Language Education Institute.

Kataoka, Kuniyoshi. 2005. Variability of spatial frames of reference in the wayfinding discourse on commercial signboards. Language in Society 34: 593-632.

Levinson, Stephen C. 2003. Space in language and cognition. Cambridge: Cambridge University Press.

Levinson, Stephen C. \& Wilkins, David. P. 2006. Grammars of space: Explorations in cognitive diversity. Cambridge: Cambridge University Press.

Pederson, Eric, Danziger, Eve, Wilkins, David, Levinson, Stephen C., Kita, Sotaro, \& Senft, Gunter. 1998. Semantic typology and spatial conceptualization. Language 74, 557-589.

Hosoma, Hiromichi. 2003. Saireikuukan wo kataru kotoba to jesuchaa - misakubochou nishiuredengaku bettou no katari [Language and gesture describing festival space: Narratives by a master of the Nishiure Dengaku in Misakubo town]. Proceedings of the Meeting of the Japanese Society for Artificial Intelligence, 47-51.

\author{
Makiko Takekuro \\ Waseda University \\ Faculty of Law \\ 1-6-1 Nishiwaseda, Shinjuku-ku, \\ Tokyo, 169-8050, Japan \\ mtakekuro@waseda.jp
}

